\title{
Luteolin inhibits cell cycle progression and induces apoptosis of breast cancer cells through downregulation of human telomerase reverse transcriptase
}

\author{
LIMING HUANG $^{1}$, KETAO JIN ${ }^{2}$ and HUANRONG LAN ${ }^{1}$ \\ Departments of ${ }^{1}$ Breast and Thyroid Surgery, and ${ }^{2}$ Colorectal Surgery, Shaoxing People's Hospital, \\ Shaoxing Hospital of Zhejiang University, Shaoxing, Zhejiang 312000, P.R. China
}

Received June 8, 2018; Accepted January 16, 2019

DOI: $10.3892 / 01.2019 .10052$

\begin{abstract}
Luteolin is a flavonoid, which has been extensively investigated due to its antitumor effects; however, the underlying mechanisms of its action remain largely unknown. The present study aimed to investigate the role of luteolin in breast cancer (BC), and explored how luteolin suppresses the growth and induces the apoptosis of BC cells. The MTS assay was used to determine the anticancer activity of luteolin. Colony formation and Transwell assays were performed to evaluate the effects of luteolin on cell growth and invasion. Cell cycle progression and apoptosis were analyzed by flow cytometry. In addition, western blotting was performed to analyze cellular apoptosis and signaling pathways elicited by luteolin. The present study revealed that the proliferation of the $\mathrm{BC}$ cell line MDA-MB-231 was effectively suppressed by luteolin in a dose-dependent manner. Additionally, luteolin was revealed to increase apoptotic rates in BC cells. Dose-dependent cell cycle arrest in $\mathrm{S}$ phase was observed following treatment with luteolin in MDA-MB-231 cells. Mechanistically, luteolin reduced telomerase levels in a dose-dependent manner. Additionally, luteolin inhibited phosphorylation of the nuclear factor- $\kappa \mathrm{B}$ inhibitor $\alpha$ and its target gene c-Myc, to suppress human telomerase reverse transcriptase (hTERT) expression,
\end{abstract}

Correspondence to: Professor Ketao Jin, Department of Colorectal Surgery, Shaoxing People's Hospital, Shaoxing Hospital of Zhejiang University, 568 Zhongxing North Road, Shaoxing, Zhejiang 312000, P.R. China

E-mail: jinketao2001@zju.edu.cn

Dr Huanrong Lan, Department of Breast and Thyroid Surgery, Shaoxing People's Hospital, Shaoxing Hospital of Zhejiang University, 568 Zhongxing North Road, Shaoxing, Zhejiang 312000, P.R. China

E-mail: lanhr2018@163.com

Abbreviations: $\mathrm{BC}$, breast cancer; hTERT, human telomerase reverse transcriptase; NF- $\kappa \mathrm{B}$, nuclear factor- $\kappa \mathrm{B}$

Key words: breast cancer, hTERT, luteolin, cell cycle, telomerase which encodes the catalytic subunit of telomerase. Collectively, the results of the present study indicated that luteolin may inhibit BC cell growth by targeting hTERT, suggesting that the mechanism of hTERT regulation by luteolin may justify further study regarding its potential as a therapeutic target for $\mathrm{BC}$ treatment.

\section{Introduction}

Breast cancer (BC) is a frequently malignant cancer, which accounts for $30 \%$ of all newly diagnosed cancer cases among women and is a major cause of cancer-associated mortality among women (1). Currently, treatment of BC primarily focuses on surgery, chemotherapy and endocrine therapy. However, the prognosis of $\mathrm{BC}$ treatment is not satisfactory, mainly due to progression and metastasis following conventional treatment $(2,3)$. The limited current knowledge of the molecular basis of $\mathrm{BC}$ restricts the development of novel treatment strategies (4). BC develops as a consequence of cellular alterations that promote cell proliferation and metastasis, and/or suppress apoptosis (5). These changes result from dysregulation of key signal transduction pathways within the cell, which transmit extracellular signals to transcription factors. Therefore, the mechanisms underlying the unlimited growth of $\mathrm{BC}$ cells require urgent elucidation to identify potential therapeutic strategies.

Continuous cell division is frequently associated with the stabilization of telomere length due to the reactivation of telomerase. Currently, repression of telomerase and shorter telomeres are considered potential anticancer mechanisms (6). Telomerase consists of several subunits, including human telomerase reverse transcriptase (hTERT) and human telomerase RNA. hTERT is a limiting factor for telomerase activity and high hTERT levels have been observed in $~ 90 \%$ of human cancer types, including BC (7). Notably, the expression levels of hTERT are closely correlated with clinical aggressiveness and poor prognosis in BC $(8,9)$. Shi et al used a specific inhibitor of telomerase activity and revealed that telomerase inhibition significantly affects BC cell growth, cell cycle and apoptosis (10). Additionally, Yu et al (11) previously demonstrated that zinc finger E-box binding homeobox 1, a multifunctional cancer stimulatory factor, promotes BC cell 
invasiveness, proliferation and apoptosis by regulating hTERT expression. Therefore, hTERT may be investigated as a potential anticancer drug target.

Luteolin (39, 49, 5, 7-tetrahydroxyflavone) is a flavone compound present in a number of medicinal plants. Flavones are a class of flavonoids, among the most abundant secondary metabolites in plants, and are widely known to be involved in various pharmacological activities (12). Luteolin exhibits a range of antitumor activities by suppressing cell proliferation and invasion, inducing cell cycle arrest and apoptosis, sensitizing drug resistance and mitigating metastasis of cancer cells $(13,14)$. In $\mathrm{BC}$, luteolin has been reported to enhance paclitaxel-induced apoptosis (15) and to sensitize drug-resistant BC cells to tamoxifen (16). In addition, luteolin may inhibit cell migration and invasion, and reverse the epithelial-mesenchymal transition of MDA-MB-231 cells (17). Although the protective role of luteolin in $\mathrm{BC}$ has been revealed, the underlying mechanism of action of luteolin on $\mathrm{BC}$ cells remains largely unclear.

It has previously been suggested that several medicinal plants and herbal ingredients, including resveratrol, crocin and papaverine, could be used as inhibitors of the telomerase enzyme and the active site of telomerase (18). However, whether luteolin has the ability to downregulate telomerase activity and hTERT expression remains unclear. The present study aimed to confirm the effects of luteolin on cell growth, invasion, cell cycle progression and apoptosis in the BC cell line MDA-MB-231. The present study additionally intended to measure the effect of consecutive treatment with luteolin on telomerase activity and hTERT expression, as well as to explore the underlying mechanisms.

\section{Materials and methods}

Cell culture and treatment. A human BC cell line (MDA-MB-231) was obtained from the Cell Bank of Chinese Academy of Sciences (Shanghai, China) and cultured in RPMI-1640 medium (Hyclone; GE Healthcare Life Sciences, Logan, UT, USA), supplemented with $10 \%$ fetal bovine serum (FBS, Gibco; Thermo Fisher Scientific, Inc., Waltham, MA, USA) and $1 \%$ penicillin and streptomycin (Hyclone; GE Healthcare Life Sciences). All cells were maintained at $37^{\circ} \mathrm{C}$ in a humidified atmosphere containing $5 \% \mathrm{CO}_{2}$. Luteolin was purchased from Cayman Chemical Co. (Ann Arbor, MI, USA), and $0.029 \mathrm{~g}$ luteolin was dissolved in $200 \mu \mathrm{l}$ dimethyl sulfoxide to obtain $0.5 \mathrm{M}$ luteolin and stored at $-20^{\circ} \mathrm{C}$. Prior to use, the stock was diluted to $1,2,4,8,16,32,64,128,256 \mu \mathrm{M}$ luteolin in 10\% FBS RPMI-1640 medium for MTS assay, and 1,10 and $30 \mu \mathrm{M}$ luteolin in FBS-free RPMI-1640 medium for all other experiments. MDA-MB-231 cell cultures received various concentrations of luteolin for 24 or $48 \mathrm{~h}$ to evaluate its effect on BC cells.

Reverse transcription-quantitative polymerase chain reaction (RT-qPCR). Total RNA was isolated from cells using TRIzol ${ }^{\circledR}$ reagent, according to the manufacturer's protocol (Invitrogen; Thermo Fisher Scientific, Inc.). The total RNA yield was determined using the NanoDrop ND-8000 UV-Vis spectrophotometer (NanoDrop Technologies; Thermo Fisher Scientific, Inc.). cDNA was synthesized using a PrimeScript
RT-PCR kit (Takara Bio, Inc., Otsu, Japan) under the following conditions: $95^{\circ} \mathrm{C}$ for $15 \mathrm{sec}$; followed by 30 cycles of $95^{\circ} \mathrm{C}$ for $5 \mathrm{sec}$ and $60^{\circ} \mathrm{C}$ for $60 \mathrm{sec}$. Quantification was performed using RT Real-Time SYBR Green assays (Bio-Rad Laboratories, Inc., Hercules, CA, USA) on the ABI PRISM 7900 HT Sequence Detection system (Applied Biosystems; Thermo Fisher Scientific, Inc.). The reaction conditions were as follows: $94^{\circ} \mathrm{C}$ for $5 \mathrm{~min}$, followed by 40 cycles at $95^{\circ} \mathrm{C}$ for $15 \mathrm{sec}, 65^{\circ} \mathrm{C}$ for $30 \mathrm{sec}$ and $72^{\circ} \mathrm{C}$ for $30 \mathrm{sec}$, and a final extension step at $72^{\circ} \mathrm{C}$ for $5 \mathrm{~min}$. Each sample was examined in triplicate and the relative mRNA expression levels were determined using the $2^{-\Delta \Delta C q}$ method (19), normalized for the housekeeping gene GAPDH. Primers used for RT-qPCR are shown in Table I.

MTS assay. The MTS assay is a colorimetric assay in which the amount of color produced is directly proportional to the number of viable cells. Briefly, $5 \times 10^{4}$ cells in the log growth phase were plated on 96-well plates. Following luteolin exposure for $24 \mathrm{~h}(17,20), 20 \mu \mathrm{l}$ MTS (Promega Corporation, Madison, WI, USA) labeling reagent was added to each well and incubated for another $4 \mathrm{~h}$. Absorbance at $490 \mathrm{~nm}$ was measured using a microplate reader (Molecular Devices, LLC, Sunnyvale, CA, USA). The half maximal inhibitory concentration $\left(\mathrm{IC}_{50}\right)$ values were determined from the concentration curves generated using GraphPad Prism software 6.0 (GraphPad Software, Inc., La Jolla, CA, USA).

Colony formation assays. Cell proliferation was monitored using a colony formation assay. Briefly, 300 cells/well were grown in 6-cm plates and maintained in Dulbecco's modified Eagle's medium (Thermo Fisher Scientific, Inc.) containing $10 \%$ FBS with or without various concentrations of luteolin. After 14 days, cells were fixed with $4 \%$ paraformaldehyde for $15 \mathrm{~min}$ at room temperature and stained with $5 \mathrm{~g} / \mathrm{l}$ crystal violet (Beyotime Institute of Biotechnology, Haimen, China) for $3 \mathrm{~min}$ at room temperature. Visible colonies were counted manually.

Transwell assays. In total, $1 \times 10^{5}$ MDA-MB-231 cells were seeded at the top of Matrigel-coated invasion chambers (24-well plates, $8 \mathrm{~mm}$ pore size; BD Biosciences, Franklin Lakes, NJ, USA) with serum-free medium containing various concentrations of luteolin. Medium containing 10\% FBS was used as a chemoattractant in the lower chambers. After $24 \mathrm{~h}$ of incubation at $37^{\circ} \mathrm{C}$ in a $5 \% \mathrm{CO}_{2}$ atmosphere, the media were removed from the wells and washed twice with PBS. The cells in the upper chambers were removed using a cotton swab. Migratory cells were fixed with $4 \%$ paraformaldehyde at room temperature for $5 \mathrm{~min}$, and stained with $5 \mathrm{~g} / 1$ crystal violet for $3 \mathrm{~min}$ at room temperature. Cells were counted in six representative fields using an inverted light microscope at x200 magnification (Olympus BX53; Olympus Corporation, Tokyo, Japan).

Western blotting. Cells were lysed using ice-cold lysis buffer (25 mM HEPES, 1.5\% Triton X-100, 0.1\% SDS, 0.5 M NaCl, $5 \mathrm{mM}$ EDTA and $0.1 \mathrm{mM}$ sodium deoxycholate). The protein concentration of each sample was quantified using a bicinchoninic acid protein assay kit (Thermo Fisher Scientific, 
Table I. Primer sequences used for reverse transcriptionquantitative polymerase chain reaction.

\begin{tabular}{ll}
\hline Gene & \multicolumn{1}{c}{ Sequence (5'-3') } \\
\hline hTERT & $\begin{array}{l}\text { Forward: CGGAAGAGTGTCTGGAGCAA } \\
\text { Reverse: CTCCCACGACGTAGTCCATG }\end{array}$ \\
c-Myc & Forward: CAATGTCAAGAGGCGAACACA \\
& $\begin{array}{l}\text { Reverse: CGTCGTTTCCGCAACAAG } \\
\text { GAPDH }\end{array}$ \\
& $\begin{array}{l}\text { Forward: CTTTGGTATCGTGGAAGGACTC } \\
\text { Reverse: GTAGAGGCAGGGGATGATGTTCT }\end{array}$ \\
\hline
\end{tabular}

hTERT, human telomerase reverse transcriptase.

Inc.). Equal quantities $(20 \mu \mathrm{g})$ of protein/lane were separated via SDS-PAGE on a $10-12 \%$ gel and were then transferred to polyvinylidene difluoride membranes. The membranes were blocked with 5\% skimmed milk in Tris-buffered saline with $0.1 \%$ Tween-20 (TBST) for $1 \mathrm{~h}$ at room temperature. After washing with TBST, the membranes were hybridized with primary antibodies against p21 (1:1,000; cat. no. ab109520; Abcam, Cambridge, UK), Survivin (1:1,000; cat. no. \#2808; CST Biological Reagents Co., Ltd., Shanghai, China), cyclin D1 (1:1,000; cat. no. \#2978; CST Biological Reagents Co., Ltd.), B-cell lymphoma 2 (BCL-2; 1:1,000; cat. no. ab32124; Abcam), Bcl-2-associated X protein (Bax; 1:1,000; cat. no. \#5023; CST Biological Reagents Co., Ltd.), caspase-3 (1:500; cat. no. \#9662; CST Biological Reagents Co., Ltd.), hTERT (1:1,000; cat. no. ab32020; Abcam), c-Myc (1:1,000; cat. no. \#2276; CST Biological Reagents Co., Ltd.), phosphorylated phosphorylated-nuclear factor $\kappa \mathrm{B}(\mathrm{NF}-\kappa \mathrm{B})$ inhibitor $\alpha(\mathrm{pI} \kappa \mathrm{B} \alpha$; 1:1,000; cat. no. \#2859; CST Biological Reagents Co., Ltd.), IкB $\alpha$ (1:1,000; cat. no. \#4814; CST Biological Reagents Co., Ltd.) and GAPDH (1:1,000; cat. no. ab9485; Abcam) overnight at $4^{\circ} \mathrm{C}$. After washing in TBST, the membranes were incubated with the appropriate horseradish peroxidase (HRP)-conjugated secondary antibodies (cat. nos. A21010 and A21020; 1:5,000; Abbkine Scientific Co., Ltd., Wuhan, China) at room temperature for $1 \mathrm{~h}$. The protein bands were visualized using Immobilon Western Chemiluminescent HRP substrate (EMD Millipore, Billerica, MA, USA) and imaged by LAS-4000 mini luminescent image analyzer (Fujifilm, Life Science, New Haven, CT, USA). ImageJ software (version 1.8.0; National Institutes of Health, Bethesda, MD, USA) was used for densitometric semi-quantification of the blots.

Apoptosis analysis. The Annexin-fluorescein isothiocyanate apoptosis detection kit (eBioscience; Thermo Fisher Scientific, Inc.) was used to evaluate apoptosis. After treatment, cells in the $0,10,30 \mu \mathrm{M}$ luteolin-treated groups were harvested and centrifuged for $5 \mathrm{~min}$ at $1,680 \mathrm{xg}$ at room temperature, and were then suspended at a density of $1 \times 10^{6}$ cells $/ \mathrm{ml}$. Subsequently, the cells were diluted in buffer, and $10 \mu \mathrm{l}$ Annexin $\mathrm{V}$ and $10 \mu 1$ propidium iodide (PI) were added to $100 \mu 1$ cell suspension. Subsequently, they were incubated for $15 \mathrm{~min}$ at room temperature in the dark. Samples were analyzed by flow cytometry using NovoExpress software (ACEA BioSciences Inc., San Diego, CA, USA). Each experiment was performed in triplicate at least. A terminal deoxynucleotidyl-transferase-mediated dUTP nick end labeling (TUNEL) apoptosis detection kit (Yeasen, Shanghai, China) was used to determine cell apoptosis. Briefly, MDA-MB-231 cells were fixed with $4 \%$ paraformaldehyde for $5 \mathrm{~min}$ at room temperature, permeabilized with $0.1 \%$ Triton $\mathrm{X}-100$ for $5 \mathrm{~min}$ at room temperature and labeled with terminal deoxynucleotidyl transferase reaction mix for $60 \mathrm{~min}$ at $37^{\circ} \mathrm{C}$. DAPI was used to stain nuclei. A Nikon Eclipse Ti-U fluorescence microscope (Nikon Corporation, Tokyo, Japan) was used to observe morphological nuclear DNA fragmentation in the stained BC cells (magnification, x200).

Cell cycle analysis. MDA-MB-231 cells were cultivated in 6-well plates. After treatment, cells were harvested and centrifuged at $1,680 \mathrm{xg}$ for $5 \mathrm{~min}$ at room temperature. The supernatant was discarded and the cell pellet was washed twice with $3 \mathrm{ml}$ PBS and centrifuged again. Subsequently, ice-cold $70 \%$ ethanol was added to fix the cells at $4^{\circ} \mathrm{C}$ for $1 \mathrm{~h}$. After washing with PBS, $1 \mathrm{ml}$ PI solution $(50 \mu \mathrm{g} / \mathrm{ml})$ containing $50 \mu \mathrm{g} / \mathrm{ml}$ RNase A (DNase free) was added to the cells for staining in the dark at room temperature for $15 \mathrm{~min}$. The distribution of cells in each cell cycle phase was measured using a flow cytometer at $488 \mathrm{~nm}$ excitation wavelength and over $630 \mathrm{~nm}$ emission wavelength. The cell cycle distribution was evaluated by calculating the proportion of cells in the $G_{0} / G_{1}, S$ and $G_{2} / M$ stages using NovoExpress software (BioSciences Inc.).

Telomeric repeat amplification protocol (TRAP)-ELISA analysis. Telomerase activity was determined by TRAP assay using the TeloTAGGG Telomerase PCR ELISA PLUS kit (Roche Diagnostics GmbH, Mannheim, Germany), according to the manufacturer's protocol. Treated cells were collected and lysed in ice-cold lysis buffer (Beyotime Institute of Biotechnology, Shanghai, China) for $30 \mathrm{~min}$. Following centrifugation $\left(10,000 \times \mathrm{g}\right.$ for $10 \mathrm{~min}$ at $\left.4^{\circ} \mathrm{C}\right)$, the supernatants were collected and stored at $-80^{\circ} \mathrm{C}$, and $\sim 5 \mu \mathrm{l}$ of each supernatant was added to the PCR reaction mixture provided in the kit. PCR was then carried out under the following reaction conditions: Primer elongation $\left(25^{\circ} \mathrm{C}\right.$ for $\left.30 \mathrm{~min}\right)$, telomerase inactivation $\left(94^{\circ} \mathrm{C}\right.$ for $\left.5 \mathrm{~min}\right), 30$ cycles of amplification $\left(94^{\circ} \mathrm{C}\right.$ for $30 \mathrm{sec}, 50^{\circ} \mathrm{C}$ for $30 \mathrm{sec}, 72^{\circ} \mathrm{C}$ for $\left.90 \mathrm{sec}\right)$ and extension $\left(72^{\circ} \mathrm{C}\right.$ for $\left.5 \mathrm{~min}\right)$. The PCR product was denatured and hybridized with the digoxigenin (DIG)-labeled telomeric repeat-specific probe. Finally, the PCR product was detected using the anti-DIG-POD antibody $\left(1: 5,000\right.$, incubated at $37^{\circ} \mathrm{C}$ for $60 \mathrm{~min}$ ) and measured at $450 \mathrm{~nm}$ on a microplate reader.

Statistical analysis. All values are expressed as the means \pm standard deviation. Statistical analysis was performed using SPSS version 19.0 (SPSS; IBM Corp., Armonk, NY, USA). One-way analysis of variance (ANOVA) and an unpaired Student's t-test were performed to compare means among all measured variables. When ANOVA results were significant, multiple comparisons of means were applied with Tukey HSD post hoc analysis. $\mathrm{P}<0.05$ was considered to indicate a statistically significant difference. 
A

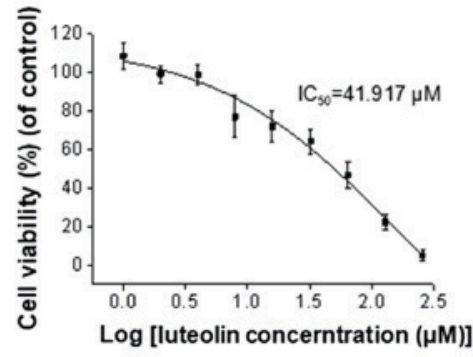

B

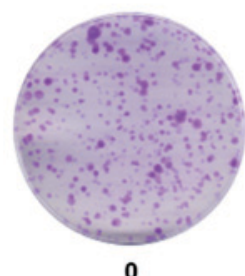

0

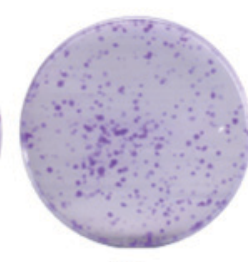

10

Luteolin $(\mu \mathrm{M})$

C

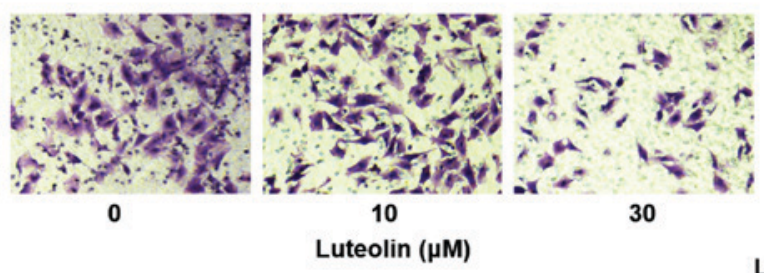

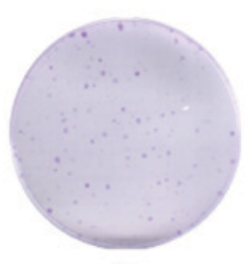

30
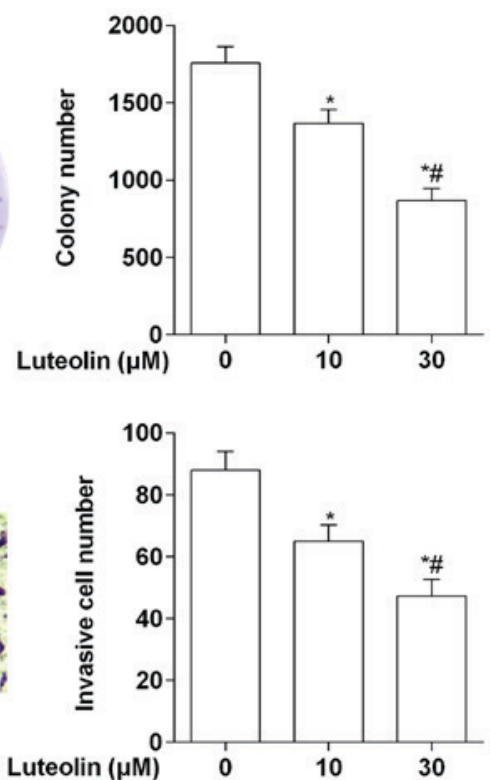

Figure 1. Inhibitory effects of luteolin on the proliferation and invasion of human breast cancer cells. (A) Dose-dependent antitumor effect of luteolin on MDA-MB-231 breast cancer cells after $24 \mathrm{~h}$. Data are presented as the means \pm standard deviation ( $\mathrm{n}=3$ ). (B) Luteolin exhibited a significant antitumor effect on the MDA-MB-231 cell line in colony formation assays. (C) Luteolin inhibited cell invasion of MDA-MB-231 cells as detected by a Transwell assay. ${ }^{*}<<0.05$ vs. the control group $\left(0 \mu \mathrm{M}\right.$ luteolin); ${ }^{\#} \mathrm{P}<0.05$ vs. the $10 \mu \mathrm{M}$ luteolin group. $\mathrm{IC}_{50}$, half maximal inhibitory concentration.

\section{Results}

Luteolin inhibits the proliferation and invasion of $B C$ cells. Firstly, the cytotoxicity of luteolin on MDA-MB-231 cells was assessed using an MTS assay. As shown in Fig. 1A, luteolin demonstrated a concentration-dependent effect on the viability of MDA-MB-231 cells. The $\mathrm{IC}_{50}$ for luteolin on MDA-MB-231 cells was $41.917 \mu \mathrm{M}$. To further assess the long-term effects of luteolin treatment on cell proliferation, a colony formation assay was performed. As expected, luteolin inhibited the colony-forming potential of MDA-MB-231 cells in a dose-dependent manner (Fig. 1B). In addition, cell invasion assay results revealed that the invasion of MDA-MB-231 cells treated with $10 \mu \mathrm{M}$ luteolin was significantly inhibited compared with the control, and the inhibition was more significant when assessing $30 \mu \mathrm{M}$ luteolin (Fig. 1C).

Luteolin blocks cell cycle progression and modulates cell cycle regulatory protein expression. The present study investigated whether luteolin-mediated growth suppression was due to cell cycle intervention. Following treatment of MDA-MB-231 cells with 10 and $30 \mu \mathrm{M}$ luteolin for $24 \mathrm{~h}$, the treated cells were subjected to cell cycle progression analysis. The results revealed that although there were significant differences between the $10 \mu \mathrm{M}$ luteolin-treated group and the control group, following $30 \mu \mathrm{M}$ luteolin treatment, MDA-MB-231 cells exhibited a 1.21-fold (34.05-41.07\%) increase in the number of cells in $\mathrm{S}$ phase, as compared with the control (Fig. 2A and B). Therefore, the expression levels of cell cycle-regulated proteins in MDA-MB-231 cells were subsequently investigated. A dose-dependent decrease in the levels of cyclin D1 and Survivin was identified, whereas the protein expression levels of p21 were increased in MDA-MB-231 cells following luteolin treatment (Fig. 2C).

Luteolin induces apoptosis of BC cells. As cell apoptosis is one of the leading mechanisms in $\mathrm{BC}$ formation, a cell apoptosis assay using flow cytometry was carried out. As shown in Fig. 3A, no significant differences were identified between the group of cells treated with $10 \mu \mathrm{M}$ luteolin for $24 \mathrm{~h}$ and the control group, with respect to the percentage of apoptotic cells. MDA-MB-231 cells treated with $30 \mu \mathrm{M}$ luteolin for $24 \mathrm{~h}$ exhibited potent cell apoptosis. In addition, luteolin treatment for $48 \mathrm{~h}$ induced cell apoptosis in a dose-dependent manner in MDA-MB-231 cells. To further validate the effects of luteolin on cell apoptosis, a TUNEL assay was performed. The results (Fig. 3B) illustrated that treatment with luteolin for $48 \mathrm{~h}$ triggered cell apoptosis in a dose-dependent manner. Following luteolin treatment, there was a decrease in BCL-2 expression and an increase in Bax protein expression in MDA-MB-231 cells. Luteolin treatment also markedly increased the ratio of Bax/BCL-2 in a concentration-dependent manner. Furthermore, caspase-3 

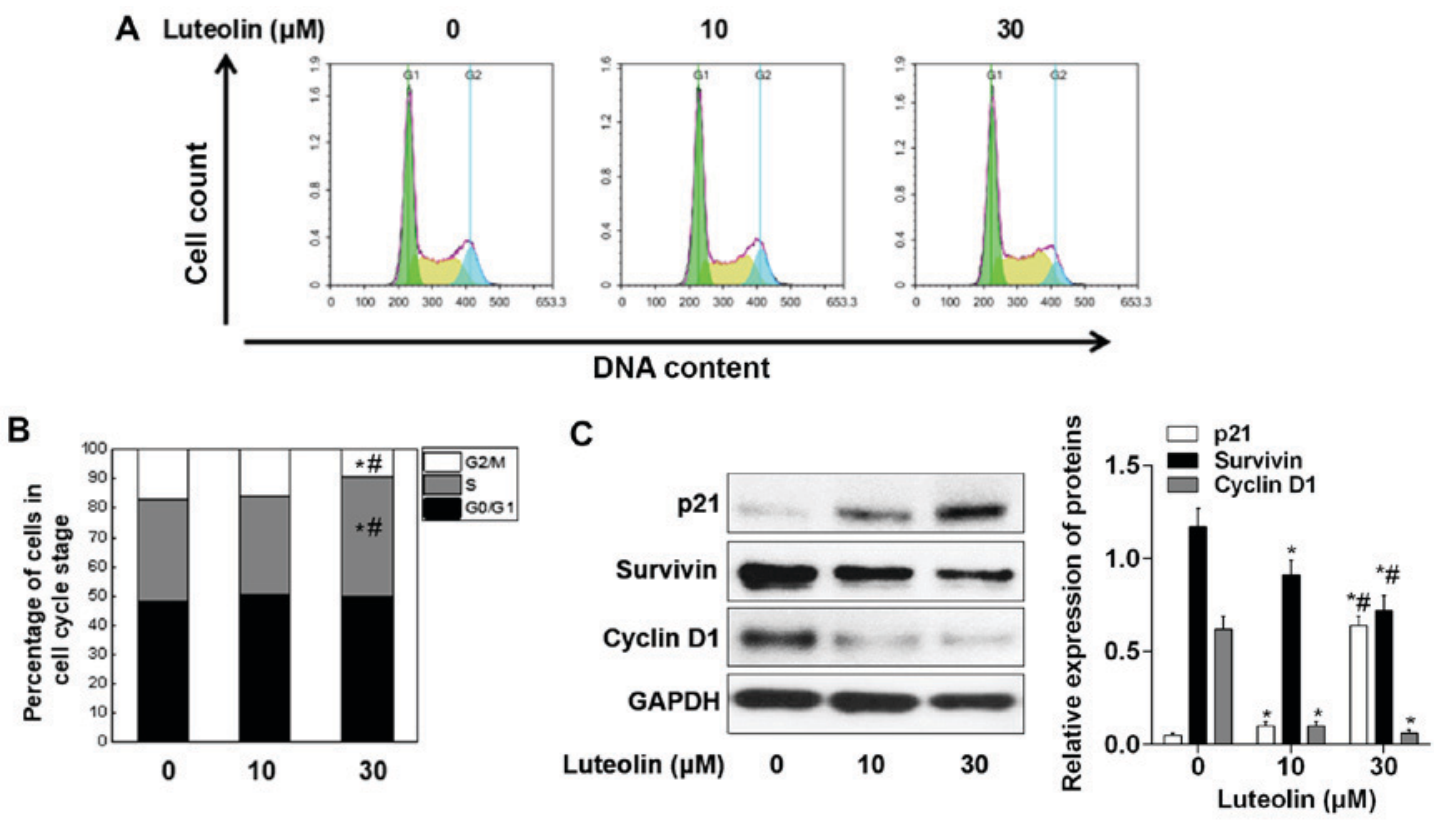

Figure 2. Luteolin inhibits cell cycle progression in breast cancer cells. (A) MDA-MB-231 cells were treated with 0,10 or $30 \mu \mathrm{M}$ luteolin and analyzed by flow cytometry to determine the distribution of cells in different phases of the cell cycle. (B) Histogram representing the mean value of three independent experiments. MDA-MB-231 cells accumulated in S phase following luteolin treatment. (C) Total protein was isolated from control and luteolin-treated MDA-MB-231 cells, and subjected to immunoblotting of p21, Survivin and cyclin D1 proteins. Membranes were stripped and re-probed with anti-GAPDH antibody to ensure equal protein loading. p21 was upregulated, whereas Survivin and cyclin D1 were downregulated in MDA-MB-231 cell in a dose-dependent manner. ${ }^{*} \mathrm{P}<0.05$ vs. the control group $\left(0 \mu \mathrm{M}\right.$ luteolin); ${ }^{*} \mathrm{P}<0.05$ vs. the $10 \mu \mathrm{M}$ luteolin group.

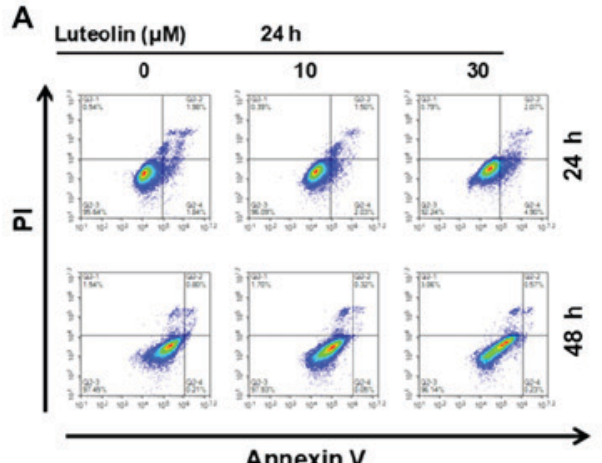

Annexin V

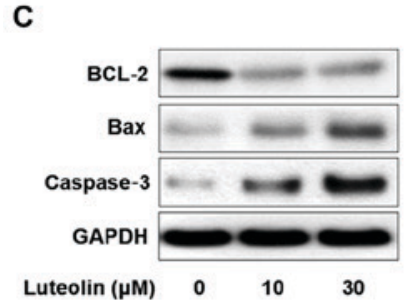

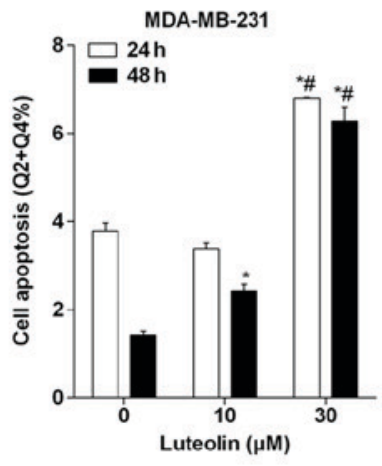

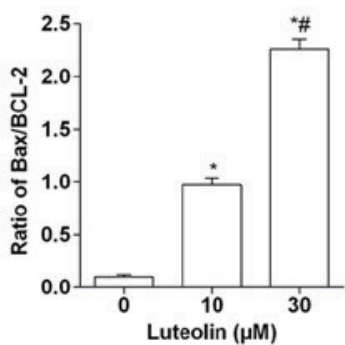

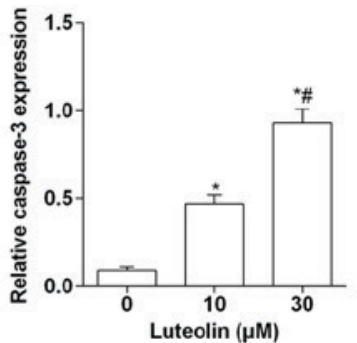
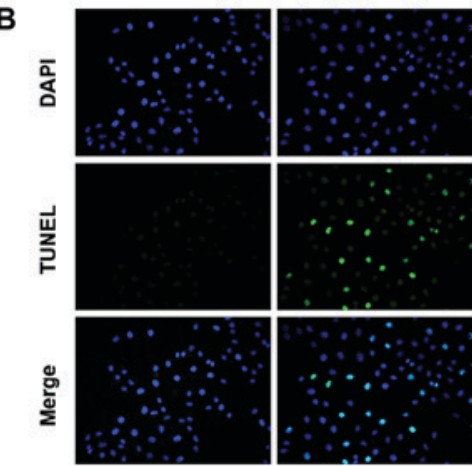

10

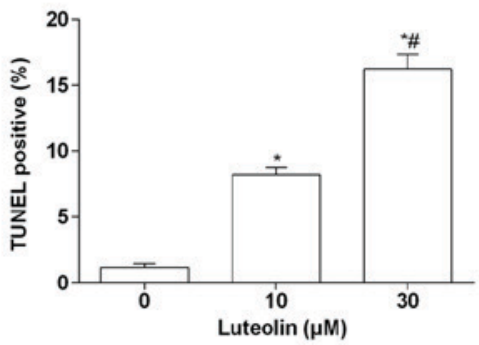

Figure 3. Luteolin induces apoptosis of breast cancer cells. (A) MDA-MB-231 cells were treated with 10 and $30 \mu \mathrm{M}$ luteolin for 24 or $48 \mathrm{~h}$ and were then analyzed by Annexin V/PI staining and flow cytometry (left). Quantitative data revealed that treatment with $30 \mu \mathrm{M}$ luteolin for $24 \mathrm{~h}$ induced significant apoptosis of MDA-MB-231 cells. A dose-dependent increase in the number of apoptotic cells after $48 \mathrm{~h}$ treatment with luteolin was observed compared with control cells (right). (B) A TUNEL assay was performed to validate the apoptosis of breast cancer cells following treatment with various concentrations of luteolin for $48 \mathrm{~h}$ (magnification, x200). (C) Western blot analysis revealed that the expression levels of apoptotic proteins, including Bax and caspase-3, were upregulated in MDA-MB-231 cells following treatment with luteolin for $48 \mathrm{~h}$ as compared with the control. ${ }^{*} \mathrm{P}<0.05$ vs. the control group $\left(0 \mu \mathrm{M}\right.$ luteolin); ${ }^{\sharp} \mathrm{P}<0.05$ vs. the $10 \mu \mathrm{M}$ luteolin group. Bax, Bcl-2-associated X protein; BCL-2, B-cell lymphoma 2; PI, propidium iodide; TUNEL, terminal deoxynucleotidyl-transferase-mediated dUTP nick end labeling.

protein expression was also increased following luteolin treatment (Fig. 3C).
Luteolin downregulates hTERT and $c$-Myc expression in $B C$ cells. Previous studies have suggested that hTERT is 
A

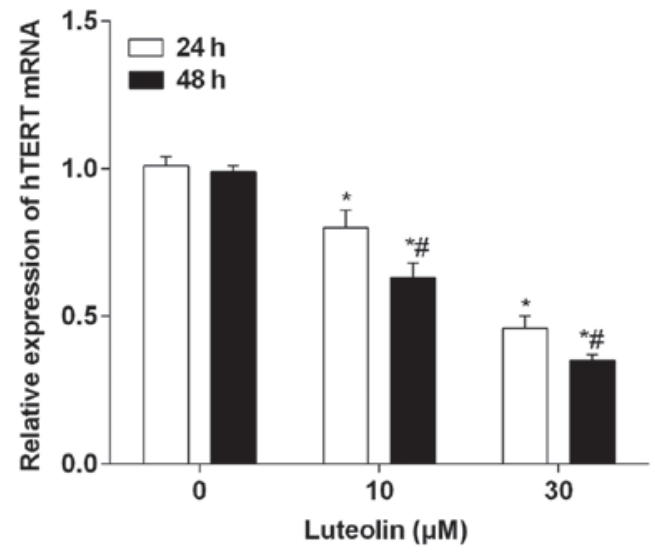

B

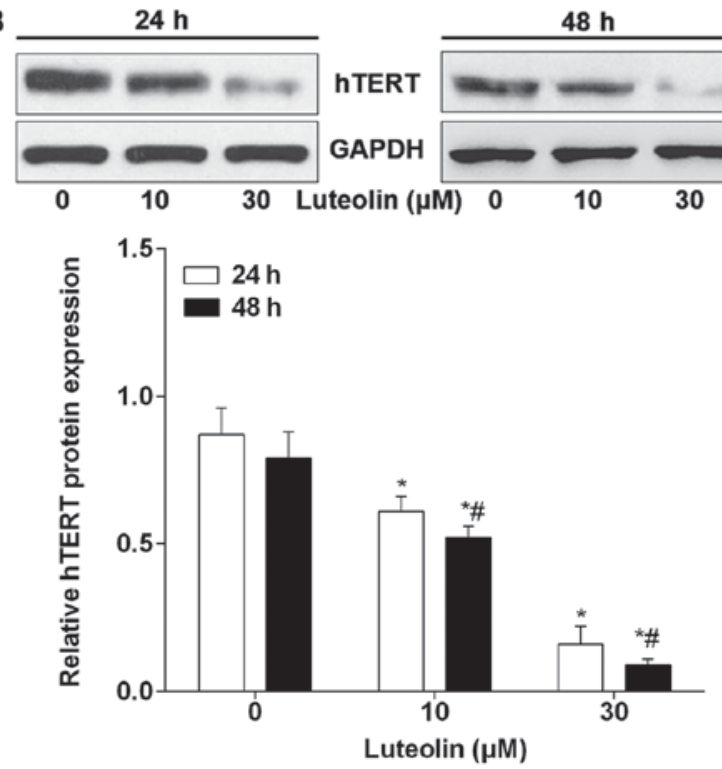

Figure 4. Luteolin inhibits hTERT expression at the transcriptional level. (A) Luteolin inhibited hTERT transcription in MDA-MB-231 cells in a concentration- and time-dependent manner, as detected by reverse transcription-quantitative polymerase chain reaction analysis. (B) Western blot analysis revealed that luteolin significantly inhibited hTERT protein levels in a dose-dependent manner after 24 and $48 \mathrm{~h} .{ }^{*} \mathrm{P}<0.05$ vs. the control group $\left(0 \mu \mathrm{M}\right.$ luteolin); ${ }^{\sharp} \mathrm{P}<0.05$ vs. the $10 \mu \mathrm{M}$ luteolin group. hTERT, human telomerase reverse transcriptase.

upregulated in BC and serves a role in regulating cell cycle, proliferation and tumorigenesis $(21,22)$. The hTERT levels were measured to reveal any potential correlative or mechanistic effects that luteolin may have on BC cells. As shown in Fig. 4A, the mRNA expression levels of hTERT were significantly downregulated following $24 \mathrm{~h}$ treatment with 10 and $30 \mu \mathrm{M}$ luteolin. Additionally, 10 and $30 \mu \mathrm{M}$ luteolin treatment for $48 \mathrm{~h}$ led to the downregulation of hTERT mRNA in MDA-MB-231 cells. A similar change in hTERT protein caused by luteolin treatment was detected (Fig. 4B). Furthermore, c-Myc has been identified as an inducer of hTERT transcription and may bind the hTERT promoter. To explore the possibility that luteolin downregulated hTERT via the c-Myc pathway, the effects of luteolin on c-Myc expression were evaluated. As expected, luteolin treatment downregulated the expression of c-Myc in a time- and dose-dependent manner at the mRNA and protein levels in MDA-MB-231 cells (Fig. 5A-C). NF- $\kappa \mathrm{B}$ signaling is one of the major upstream targets of c-Myc and a number of studies have demonstrated that luteolin targets NF- $\kappa \mathrm{B}(23-25)$. NF- $\kappa \mathrm{B}$ normally binds to $\mathrm{I} \kappa \mathrm{B} \alpha$ and is localized in the cytoplasm. Following activation, $\mathrm{I} \kappa \mathrm{B} \alpha$ is phosphorylated and dissociates from $\mathrm{NF}-\kappa \mathrm{B}$, which allows $\mathrm{NF}-\kappa \mathrm{B}$ to translocate from the cytoplasm to the nucleus to target downstream genes. Therefore, the alteration of I $\mathrm{B} \alpha$ and $\mathrm{pI} \kappa \mathrm{B} \alpha$ were evaluated by western blotting following luteolin treatment. As shown in Fig. 5B and D, although no significant change in $\mathrm{pI} \kappa \mathrm{B} \alpha$ was identified following $10 \mu \mathrm{M}$ luteolin treatment for $24 \mathrm{~h}$, the levels of $\mathrm{pI} \kappa \mathrm{B} \alpha$ were significantly decreased following treatment with luteolin for $48 \mathrm{~h}$, in a dose-dependent manner.

Luteolin reduces telomerase activity in BC cells. Since hTERT is the catalytic and limiting component of telomerase, telomerase activity in MDA-MB-231 cells was measured to fully examine the luteolin-mediated repression of hTERT. As illustrated in Fig. 6A, telomerase activity was reduced in a dose-dependent manner following treatment with luteolin for 48 h. In addition, as shown in Fig. 6B, treatment with luteolin for $72 \mathrm{~h}$ also reduced the activity levels of telomerase in a dose-dependent manner.

\section{Discussion}

$\mathrm{BC}$ is the most common type of cancer and the second most common cause of cancer-associated mortality in women. Therefore, investigating the molecular mechanisms underlying the initiation and development of $\mathrm{BC}$, and searching for more efficient therapeutic agents and strategies are of important clinical value (26). Traditional herbal medicines have long been utilized to prevent and treat neoplasms. Searching for natural products directed at suppressing proliferation and inducing apoptosis of cancer cells may be a novel strategy for $\mathrm{BC}$ treatment (27). Luteolin is a natural flavonoid that exists in several types of vegetables, fruits and medicinal herbs, and inhibits tumorigenesis in various types of cancer, including BC $(17,28,29)$. The present study validated the effect of luteolin on cell proliferation, invasion, cell cycle progression and apoptosis in BC cells in vitro. Luteolin significantly inhibited cell growth, invasion and cell cycle progression, and effectively induced apoptosis of MDA-MB-231 BC cells. In the present study, it was identified that luteolin reduced telomerase levels in a dose-dependent manner. The mechanism for this may include downregulation of hTERT expression via inhibition of the NF- $\kappa \mathrm{B}-\mathrm{c}-\mathrm{Myc}$ axis. The results provided evidence for a novel mechanism via which luteolin exerts its anticancer properties.

Notably, the dose applied in the present study was determined by an MTS assay. The results of the present study suggested that high concentrations of luteolin $(>42 \mu \mathrm{M})$ exhibited cytotoxic effects on MDA-MB-231 cells. This differed 


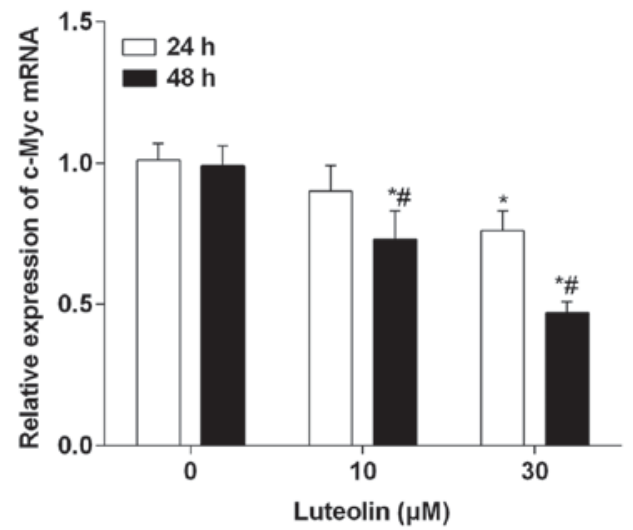

C

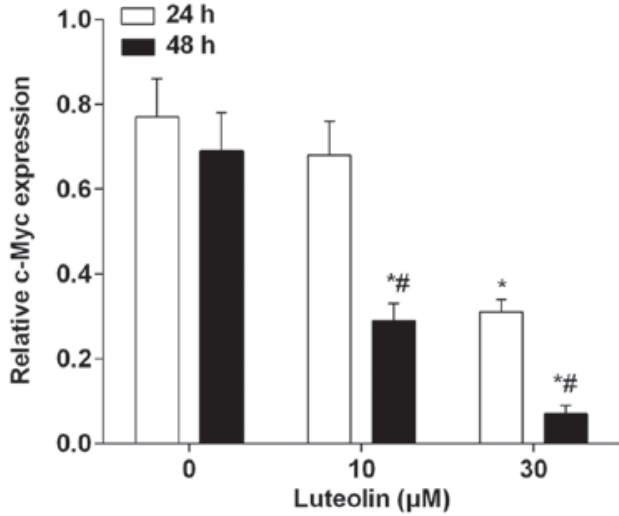

B
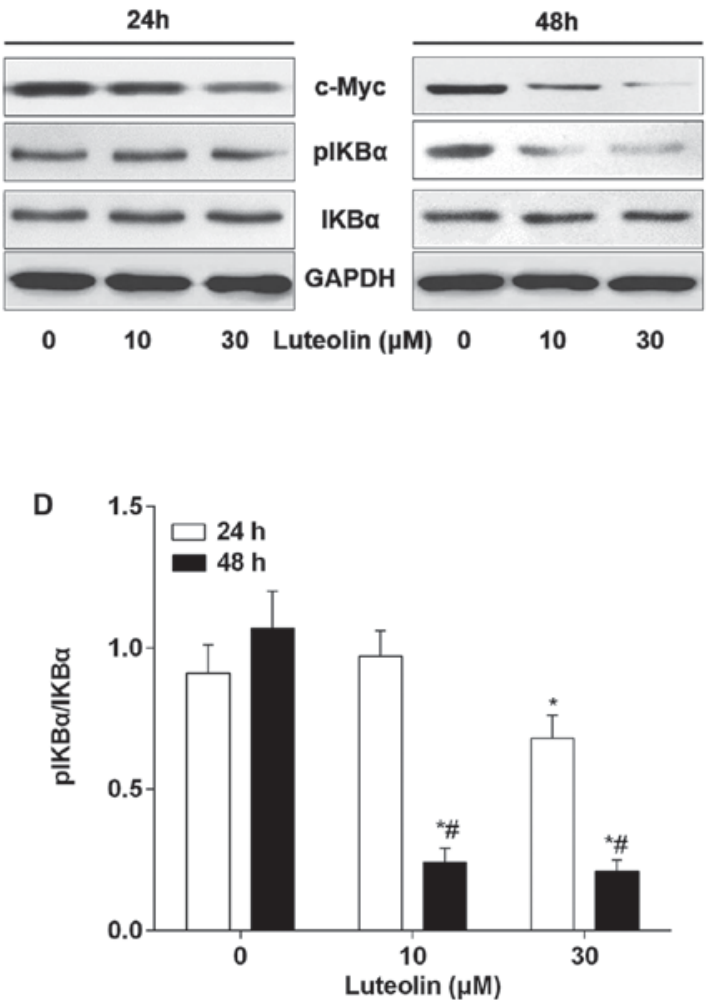

Figure 5. Luteolin targets NF- $\mathrm{B} / \mathrm{c}-\mathrm{Myc}$ to inhibit hTERT transcription. (A) Luteolin (10 $\mu \mathrm{M})$ had no effect on c-Myc mRNA expression in MDA-MB-231 cells after $24 \mathrm{~h}$. Luteolin significantly inhibited c-Myc in MDA-MB-231 cells after $48 \mathrm{~h}$, with high significance observed at $30 \mu \mathrm{M}$. (B) Western blot analysis revealed that luteolin treatment had no marked effects on the NF- $\mathrm{B} / \mathrm{c}-\mathrm{Myc}$ pathway after $24 \mathrm{~h}$. (C) Luteolin suppressed c-Myc protein levels in a dose-dependent manner after $48 \mathrm{~h}$ and (D) inhibited the activation of $\mathrm{NF}-\kappa \mathrm{B}$, as demonstrated by the inhibition of pI $\kappa \mathrm{B} \alpha$. ${ }^{*} \mathrm{P}<0.05$ vs. the control group $\left(0 \mu \mathrm{M}\right.$ luteolin); ${ }^{\#} \mathrm{P}<0.05$ vs. the $10 \mu \mathrm{M}$ luteolin group. pI $\mathrm{B} \alpha$, phosphorylated-nuclear factor- $\kappa \mathrm{B}$ inhibitor $\alpha$.
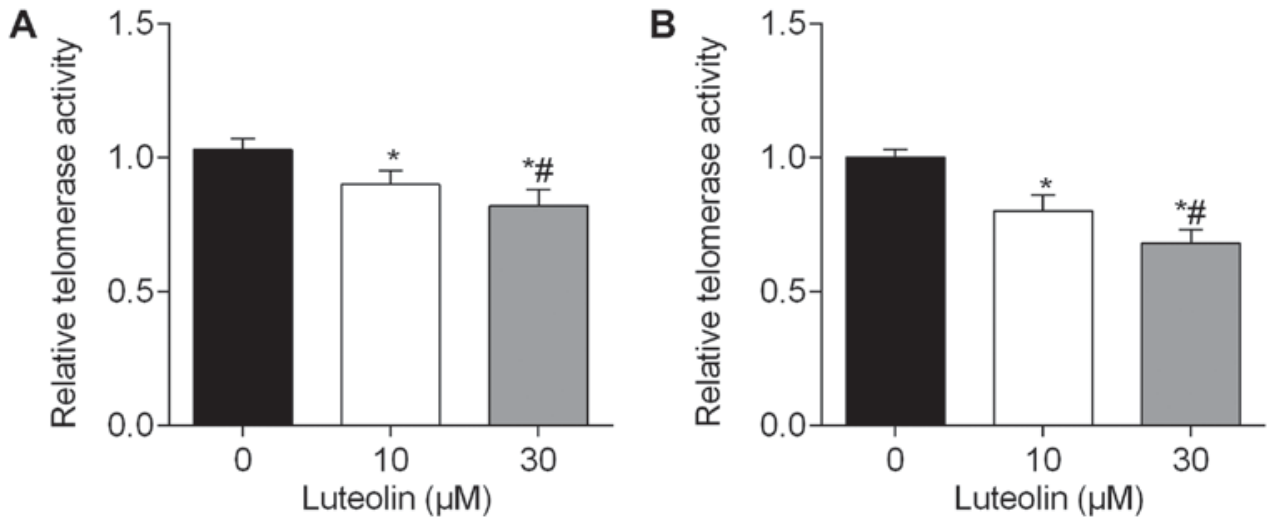

Figure 6. Luteolin reduces telomerase activity in breast cancer cells. (A) Luteolin reduced the relative levels of telomerase in MDA-MB-231 cells in a concentration-dependent manner after $48 \mathrm{~h}$. (B) Luteolin reduced the relative levels of telomerase in MDA-MB-231 cells after $72 \mathrm{~h}$. Values are representative of three independent experiments and shown as a percentage of the mean \pm standard deviation. ${ }^{*} \mathrm{P}<0.05$ vs. the control group ( $0 \mu \mathrm{M}$ luteolin); ${ }^{\#} \mathrm{P}<0.05$ vs. the $10 \mu \mathrm{M}$ luteolin group.

from the study performed by Park et al (28), which identified an $\mathrm{IC}_{50}$ value of $27 \mu \mathrm{M}$ in MDA-MB-231 cells. This discrepancy may be due to different manufacturers of luteolin. Consistent with previous studies $(17,29,30)$, the antiproliferative activity of luteolin on BC cells was confirmed using a colony formation assay. In addition, the present study revealed that luteolin significantly inhibited invasion of BC cells. A previous study indicated that luteolin exerts antitumor activities by interfering with the cell cycle (31). Park et al demonstrated that luteolin induces cell cycle arrest in MCF-7 BC cells (28). In the present study, it was identified that, although luteolin treatment caused abnormal cell cycle arrest in MDA-MB-231 cells, it decreased the essential cell cycle regulators cyclin D1 and Survivin in a dose-dependent manner, which partly explained the mechanism through which luteolin affects the cell cycle of BC cells.

Notably, it was also revealed that luteolin decreased the expression levels of another novel cell cycle participator, hTERT. hTERT is critical to the survival and progression of 
cancer cells, due to being involved in the maintenance of the telomeric ends of chromosomes following each replication, which solves the end replication problem. Notably, hTERT is particularly valuable as a target for the prevention or treatment of unlimited cell cycle progression that sustains cancer (32). Bai et al (33). Identified that decreased hTERT transcription was indirectly caused by a significant decrease in activation of the upstream NF- $\mathrm{B}$ pathway, which resulted from decreased phosphorylation of $\mathrm{I} \kappa \mathrm{B} \alpha$. In addition, a previous study also demonstrated that activated $\mathrm{NF}-\kappa \mathrm{B}$ may bind to the c-Myc promoter to activate its expression, and that c-Myc preferentially binds to the hTERT promoter, increasing hTERT mRNA expression (34). In the present study it was identified that luteolin treatment in BC cells inhibited the NF- $\kappa \mathrm{B}$ pathway, and subsequent c-Myc expression, to significantly decrease hTERT expression levels. Although this was not the first time that luteolin was shown to inhibit activation of the NF- $\kappa \mathrm{B}$ signaling pathway (12), to the best of our knowledge, the present study was the first to demonstrate that luteolin may reduce telomerase levels in BC cells, providing evidence for a potential mechanism for the antitumor effects of luteolin.

Using flow cytometry and western blotting, the present study also confirmed that luteolin may induce significant apoptosis of BC cells. Notably, luteolin upregulated the pro-apoptotic factor Bax and downregulated the survival factor BCL-2, leading to a prominent increase in the ratio of Bax/BCL-2 in BC cells, suggesting that luteolin modulated mitochondrial function to mediate cell death. It has also been suggested that luteolin may be suitable to treat the resistance of human BC cells $(16,35)$. Notably, Tu et al previously identified that luteolin may sensitize drug-resistant human BC cells to tamoxifen (16). Sabzichi et al suggested that luteolin could sensitize MDA-MB 231 cells to doxorubicin by suppressing nuclear factor erythroid 2-related factor 2 mediated signaling (35). The association between apoptosis and telomerase activity has been firmly established by researchers, since numerous anticancer agents induce apoptosis through downregulation of telomerase activity $(36,37)$. Moon et al reported that gefitinib could induce cell apoptosis by decreasing telomerase activity in MDA-MB-231 cells (38). Similarly, Moradzadeh et al demonstrated that epigallocatechin3-gallate treatment significantly increased apoptosis of T47D BC cells and decreased expression of hTERT mRNA, indicating that it may serve as a novel agent which decreases resistance to chemotherapy (39). The regulation of hTERT by luteolin treatment involved in chemotherapy resistance during $\mathrm{BC}$ treatment should be investigated in vitro and in vivo.

In conclusion, the present study demonstrated that luteolin inhibited BC proliferation, invasion and cell cycle progression, and induced cell apoptosis, through suppressing activation of $\mathrm{NF}-\kappa \mathrm{B} / \mathrm{c}-\mathrm{Myc}$ and subsequent inhibition of hTERT transcription. These results suggested that luteolin may be a useful, natural and chemopreventive agent for the treatment of breast cancer.

\section{Acknowledgements}

Not applicable.

\section{Funding}

This work was supported by Zhejiang Provincial Science and Technology Projects of Traditional Chinese Medicine (grant no. 2017ZB089), the National Natural Science Foundation of China (grant nos. 81772537 and 81374014), Zhejiang Provincial Medical and Healthy Science and Technology Projects (grants nos. 2018ZD047 and 2016ZDB013), and Zhejiang Provincial Science and Technology Projects (grant nos. LGF18H160041, 2017C33212, 2017C33213 and 2015C33264).

\section{Availability of data and materials}

All data generated or analyzed during this study are included in the published article.

\section{Authors' contributions}

$\mathrm{KJ}$ designed the study and performed the statistical analysis. LH and HL performed all experiments and data correction. KJ and HL wrote the manuscript. All authors read and approved the final manuscript.

\section{Ethics approval and consent to participate}

Not applicable.

\section{Patient consent for publication}

Not applicable.

\section{Competing interests}

The authors declare that they have no competing interests.

\section{References}

1. Siegel RL, Miller KD and Jemal A: Cancer statistics, 2018. CA Cancer J Clin 68: 7-30, 2018.

2. DeSantis CE, Fedewa SA, Goding Sauer A, Kramer JL, Smith RA and Jemal A: Breast cancer statistics, 2015: Convergence of incidence rates between black and white women. CA Cancer J Clin 66: 31-42, 2016.

3. Nagini S: Breast cancer: Current molecular therapeutic targets and new players. Anticancer Agents Med Chem 17: 152-163, 2017.

4. Perou CM, Sørlie T, Eisen MB, van de Rijn M, Jeffrey SS, Rees CA, Pollack JR, Ross DT, Johnsen H, Akslen LA, et al: Molecular portraits of human breast tumours. Nature 406: 747-752, 2000.

5. Lin CH, Chang CY, Lee KR, Lin HJ, Chen TH and Wan L: Flavones inhibit breast cancer proliferation through the Akt/FOXO3a signaling pathway. BMC Cancer 15: 958, 2015.

6. Shay JW: Role of telomeres and telomerase in aging and cancer. Cancer Discov 6: 584-593, 2016.

7. Xu B, Peng M and Song Q: The co-expression of telomerase and ALT pathway in human breast cancer tissues. Tumour Biol 35: 4087-4093, 2014

8. Kulić A, Plavetić ND, Gamulin S, Jakić-Razumović J, Vrbanec D and Sirotković-Skerlev M: Telomerase activity in breast cancer patients: Association with poor prognosis and more aggressive phenotype. Med Oncol 33: 23, 2016.

9. Lu L, Zhang C, Zhu G, Irwin M, Risch H, Menato G, Mitidieri M, Katsaros D and Yu H: Telomerase expression and telomere length in breast cancer and their associations with adjuvant treatment and disease outcome. Breast Cancer Res 13: R56, 2011. 
10. Shi Y, Sun L, Chen G, Zheng D, Li L and Wei W: A combination of the telomerase inhibitor, BIBR1532, and paclitaxel synergistically inhibit cell proliferation in breast cancer cell lines. Target Oncol 10: 565-573, 2015.

11. Yu P, Shen X, Yang W, Zhang Y, Liu C and Huang T: ZEB1 stimulates breast cancer growth by up-regulating hTERT expression. Biochem Biophys Res Commun 495: 2505-2511, 2018.

12. Aziz N, Kim MY and Cho JY: Anti-inflammatory effects of luteolin: A review of in vitro, in vivo, and in silico studies. J Ethnopharmacol 225: 342-358, 2018.

13. Ma L, Peng H, Li K, Zhao R, Li L, Yu Y, Wang X and Han Z: Luteolin exerts an anticancer effect on NCI-H460 human non-small cell lung cancer cells through the induction of Sirt1-mediated apoptosis. Mol Med Rep 12: 4196-4202, 2015.

14. Lin Y, Shi R, Wang X and Shen HM: Luteolin, a flavonoid with potential for cancer prevention and therapy. Curr Cancer Drug Targets 8: 634-646, 2008.

15. Yang MY, Wang CJ, Chen NF, Ho WH, Lu FJ and Tseng TH: Luteolin enhances paclitaxel-induced apoptosis in human breas cancer MDA-MB-231 cells by blocking STAT3. Chem Biol Interact 213: 60-68, 2014

16. Tu SH, Ho CT, Liu MF, Huang CS, Chang HW, Chang $\mathrm{CH}$, $\mathrm{Wu} \mathrm{CH}$ and $\mathrm{Ho}$ YS: Luteolin sensitises drug-resistant human breast cancer cells to tamoxifen via the inhibition of cyclin E2 expression. Food Chem 141: 1553-1561, 2013.

17. Lin D, Kuang G, Wan J, Zhang X, Li H, Gong X and Li H: Luteolin suppresses the metastasis of triple-negative breast cancer by reversing epithelial-to-mesenchymal transition via downregulation of $\beta$-catenin expression. Oncol Rep 37: 895-902, 2017.

18. Ganesan K and Xu B: Telomerase inhibitors from natural products and their anticancer potential. Int J Mol Sci 19: pii: E13, 2017.

19. Livak KJ and Schmittgen TD: Analysis of relative gene expression data using real-time quantitative PCR and the 2(-Delta Delta C(T)) method. Methods 25: 402-408, 2001.

20. Sun DW, Zhang HD, Mao L, Mao CF, Chen W, Cui M, Ma R, Cao HX, Jing CW, Wang Z, et al: Luteolin inhibits breast cancer development and progression in vitro and in vivo by suppressing notch signaling and regulating MiRNAs. Cell Physiol Biochem 37: 1693-1711, 2015.

21. Kyo S, Takakura M, Fujiwara T and Inoue M: Understanding and exploiting hTERT promoter regulation for diagnosis and treatment of human cancers. Cancer Sci 99: 1528-1538, 2008

22. Vageli D, Ioannou MG and Koukoulis GK: Transcriptional activation of hTERT in breast carcinomas by the Her2-ER81-related pathway. Oncol Res 17: 413-423, 2009.

23. Lou L, Liu Y, Zhou J, Wei Y, Deng J, Dong B and Chai L: Chlorogenic acid and luteolin synergistically inhibit the proliferation of interleukin-1 $\beta$-induced fibroblast-like synoviocytes through regulating the activation of $N F-\kappa B$ and JAK/STAT-signaling pathways. Immunopharmacol Immunotoxicol 37: 499-507, 2015.

24. Zhang X, Du Q, Yang Y, Wang J, Dou S, Liu C and Duan J: The protective effect of Luteolin on myocardial ischemia/reperfusion (I/R) injury through TLR4/NF- $\kappa \mathrm{B} / \mathrm{NLRP} 3$ inflammasome pathway. Biomed Pharmacother 91: 1042-1052, 2017.

25. Chen T, Li B, Xu Y, Meng S, Wang Y and Jiang Y: Luteolin reduces cancer-induced skeletal and cardiac muscle atrophy in a Lewis lung cancer mouse model. Oncol Rep 40: 1129-1137, 2018

26. Goel S, Wang Q, Watt AC, Tolaney SM, Dillon DA, Li W, Ramm S, Palmer AC, Yuzugullu H, Varadan V, et al: Overcoming therapeutic resistance in HER2-positive breast cancers with CDK4/6 inhibitors. Cancer Cell 29: 255-269, 2016.
27. Hasanpourghadi M, Pandurangan AK and Mustafa MR Modulation of oncogenic transcription factors by bioactive natural products in breast cancer. Pharmacol Res 128: 376-388, 2018.

28. Park SH, Ham S, Kwon TH, Kim MS, Lee DH, Kang JW, Oh SR and Yoon DY: Luteolin induces cell cycle arrest and apoptosis through extrinsic and intrinsic signaling pathways in MCF-7 breast cancer cells. J Environ Pathol Toxicol Oncol 33: 219-231, 2014.

29. Cook MT, Liang Y, Besch-Williford C, Goyette S, Mafuvadze B and Hyder SM: Luteolin inhibits progestin-dependent angiogenesis, stem cell-like characteristics, and growth of human breast cancer xenografts. Springerplus 4: 444, 2015.

30. Cook MT, Liang Y, Besch-Williford C and Hyder SM: Luteolin inhibits lung metastasis, cell migration, and viability of triple-negative breast cancer cells. Breast Cancer (Dove Med Press) 9: 9-19, 2016.

31. Ding S, Hu A, Hu Y, Ma J, Weng P and Dai J: Anti-hepatoma cells function of luteolin through inducing apoptosis and cell cycle arrest. Tumour Biol 35: 3053-3060, 2014.

32. Ren X, Zhang Z, Tian J, Wang H, Song G, Guo Q, Tian J, Han Y, Liao Q, Liu G, et al: The downregulation of c-Myc and its target gene hTERT is associated with the antiproliferative effects of baicalin on HL-60 cells. Oncol Lett 14: 6833-6840, 2017.

33. Bai D, Ueno L and Vogt PK: Akt-mediated regulation of NFkappaB and the essentialness of NFkappaB for the oncogenicity of PI3K and Akt. Int J Cancer 125: 2863-2870, 2009.

34. Papanikolaou V, Athanassiou E, Dubos S, Dimou I, Papathanasiou I, Kitsiou-Tzeli S, Kappas C and Tsezou A: hTERT regulation by $\mathrm{NF}-\kappa \mathrm{B}$ and c-myc in irradiated HER2-positive breast cancer cells. Int J Radiat Biol 87: 609-621, 2011.

35. Sabzichi M, Hamishehkar H, Ramezani F, Sharifi S, Tabasinezhad M, Pirouzpanah M, Ghanbari P and Samadi N: Luteolin-loaded phytosomes sensitize human breast carcinoma MDA-MB 231 cells to doxorubicin by suppressing Nrf2 mediated signalling. Asian Pac J Cancer Prev 15: 5311-5316, 2014.

36. Jagadeesh S, Kyo S and Banerjee PP: Genistein represses telomerase activity via both transcriptional and posttranslational mechanisms in human prostate cancer cells. Cancer Res 66: 2107-2115, 2006.

37. Yeo M, Rha SY, Jeung HC, Hu SX, Yang SH, Kim YS, An SW and Chung HC: Attenuation of telomerase activity by hammerhead ribozyme targeting human telomerase RNA induces growth retardation and apoptosis in human breast tumor cells. Int J Cancer 114: 484-489, 2005.

38. Moon DO, Kim MO, Heo MS, Lee JD, Choi YH and Kim GY: Gefitinib induces apoptosis and decreases telomerase activity in MDA-MB-231 human breast cancer cells. Arch Pharm Res 32: 1351-1360, 2009

39. Moradzadeh M, Hosseini A, Erfanian S and Rezaei $\mathrm{H}$ : Epigallocatechin-3-gallate promotes apoptosis in human breast cancer T47D cells through down-regulation of PI3K/AKT and Telomerase. Pharmacol Rep 69: 924-928, 2017.

This work is licensed under a Creative Commons Attribution-NonCommercial-NoDerivatives 4.0 International (CC BY-NC-ND 4.0) License. 